\title{
LETRAMENTO MIDIÁTICO NO ENSINO DE PORTUGUÊS: A FORMAÇÃO DA CONTRAPALAVRA CRÍTICA
}

\author{
MEDIA LITERACY IN THE TEACHING OF PORTUGUESE: \\ THE FORMATION OF CRITICAL COUNTER-WORD
}

\begin{abstract}
Facqueline Peixoto Barbosa* e Pedro Fenrique de Oliveira Simões** Universidade Estadual de Campinas, Campinas, SP, Brasil
\end{abstract}

\begin{abstract}
Resumo: Neste trabalho, tomando como ponto de partida a entrada dos textos jornalisticos no ensino de português, no Brasil, e suas diferentes perspectivas de abordagem nas últimas décadas, situados na perspectiva enunciativo-discursiva de ensino de língua, pretendemos discutir fundamentos do letramento midiático e perspectivas de trabalho com a esfera jornalistica, em sala de aula. 0 acento apreciativo deste texto é 0 de que esse trabalho deve estar voltado não só para uma apropriação contextualizada dos gêneros jornalísticos, mas também, e principalmente, para a vivência significativa de pró́ica sociais próprias dessa esfera e para a problematização crítica dos usos da língua, no diálogo com outras linguagens, a fim de que se formem sujeitos capazes de construir, nas práticas de leitura e de produção de textos, contrapalauras reflexivas e críticas acerca das questões éticas, estéticas e políticas com as quais se depara em suas práticas de letramentos.
\end{abstract}

Palavras-chave: letramento midiático; esfera jornalística; ensino de português.

Abstract: In this work, taking as a starting point the entry of journalistic texts into the teaching of Portuguese language in Brazil and its different approach perspectives on the last decades, situated in the enunciative-discursive perspective of language teaching, we intend to discuss fundamentals of media literacy and perspectives of work with the journalistic sphere in classroom. The appreciative accent of this text is that this pedagogical work must be focused not only on a contextualized appropriation of journalistic genres, but also, and mainly, for the meaningful experience of social practices of this sphere and on the critical problematization of the uses of language, in dialogue with other languages, in order to form subjects capable of constructing, in the practices of reading and producing texts, reflexive and critical counter-words on the ethical, aesthetic and political issues with which they are confronted in their literacy practice.

Keywords: Media literacy; Journalistic Sphere; Portuguese Teaching.

* Professora do Departamento de Linguística Aplicada (IEL) da Universidade Estadual de Campinas - UNICAMP, Campinas, SP, Brasil; jacbarbosa@gmail.com

* * Mestrando do Programa de Pós-graduação em Linguística Aplicada (PPLA) da Universidade Estadual de Campinas - UNICAMP, Campinas, SP, Brasil; pedrohenrisimoes@gmail.com 
Linha D'Água (Online), São Paulo, v. 30, n. 2, p. 71-91, out. 2017

\section{Introdução}

Neste trabalho, tomando como ponto de partida a presença dos textos jornalísticos no ensino de português, no Brasil, e situados na perspectiva enunciativo-discursiva de ensino de língua, apresentamos reflexões sobre duas questões centrais: i. como vem se dando o trabalho com o texto jornalístico na escola - o que se ensina e que formação se pretende propiciar para os alunos? ii. tendo em vista a perspectiva de ampliação do letramento midiático dos alunos, o que precisa ser modificado, acrescentado?

No que se refere à primeira questão, iremos analisar se o ensino de Língua Portuguesa tem se configurado como espaço para a formação de letramentos midiáticos críticos, voltados para a inserção ativa-responsiva de sujeitos nas práticas discursivas dessa esfera, a partir da análise de documentos curriculares mais recentes. No percurso de busca de respostas para a primeira questão, discutiremos a necessária abordagem dos gêneros da esfera jornalística na escola sob o viés enunciativo-discursivo de linguagem, considerando-se o diálogo entre os acontecimentos dos enunciados e sua historicidade a partir das apreciações valorativas que fundamentam os interesses dessa esfera, no Brasil, para, ao final, destacarmos o que mais para além de tal abordagem com o gênero deve estar presente na escola na perspectiva dos letramentos midiáticos críticos.

\section{Na fabricação da disciplina de português, a presença do texto jornalístico}

A partir da década de 1970, como resposta a demandas colocadas pelo mercado de trabalho e pelo desenvolvimento da industrialização (com destaque para a indústria da comunicação), no contexto sociopolítico da ditadura militar, uma maior diversidade de textos passou a figurar nos currículos de Língua Portuguesa, fazendo com que os textos literários perdessem sua hegemonia. Foi nessa época que os textos jornalísticos ganharam presença na sala de aula, na medida em que buscava-se formar sujeitos capazes de ler textos de diferentes gêneros, sobretudo aqueles de maior circulação social: notícias, HQs, anúncios, tirinhas etc.

O objetivo do trabalho com o texto jornalístico, no contexto do desenvolvimento econômico de então, era formar sujeitos capazes de ler textos dessa esfera e depreender seus significados, suas informações, seguindo o modelo comunicativo

BARBOSA, J. P.; SIMÕES, P. H. O. Letramento midiático no ensino de português: 
em que a comunicação pela linguagem se dá através da codificação de mensagens, realizada por um emissor e transmitida a um receptor. O leitor, nessa perspectiva, não passa de um sujeito passivo, que teoricamente decodifica as mensagens de forma transparente, se não houver a interferência de algum ruído, e neutra. Como é sabido, não há locutor que produza enunciados neutros, como também não há interlocutor que os compreenda de forma passiva. O processo de interlocução, na verdade, é, antes de tudo, um processo de apreciação valorativa (um "pensamento participativo", ético e responsável), que pode estar orientado para o consenso ou para a discordância, como apontam os estudos de Bakhtin e do Círculo (BAKHTIN, 1997, 2010; BAKHTIN [VOLOSHINOV], 2006).

Ao procurar formar sujeitos capazes de depreender informações de textos jornalísticos de forma "transparente" - formando, por assim dizer, um mercado consumidor do jornal -, buscava-se, na verdade, formar sujeitos orientados para o consenso, sem perspectiva de reflexão crítica em face dos enunciados jornalísticos com os quais os alunos viessem a interagir. Havia, portanto, um projeto político -ideológico definido que, com o objetivo de solidificar a massa trabalhadora, não tinha em mente a formação para a cidadania crítica, mas para a instrumentalização dessa classe com a finalidade de desenvolver o capital. É preciso acrescentar que todo esse processo contava com contextos sociopolíticos e epistemológicos viáveis para a formação desse leitor, uma vez que não havia liberdade de imprensa ${ }^{1}$ (as informações, veiculadas pelos jornais, eram controladas pelo regime ditatorial) e, também, havia pouca produção intelectual linguística e pedagógica consistente que viesse a problematizar o ensino de português.

Todo o projeto de sociedade e conhecimento que deu base para a constituição do fazer-pedagógico da língua portuguesa, ao longo de sua tradição escolar, foi norteado por princípios positivistas, tendo em mente que a própria construção das disciplinas escolares resultou do modus operandi positivista predominante nas ciências humanas daquele tempo - que procuravam encontrar seu lugar no campo das

\footnotetext{
1 Como mostramos mais à frente, o controle dos jornais, de modo a atender os interesses do regime militar, caminhou ao lado do desenvolvimento tecnológico dos meios de comunicação, em meio ao propósito de crescimento industrial, atendendo, portanto, também aos interesses do mercado midiático brasileiro.
}

BARBOSA, J. P.; SIMÕES, P. H. O. Letramento midiático no ensino de português: 
ciências (GERALDI, 2010). Reflexo disso é a própria pedagogia da fragmentação, apontada por Kleiman e Moraes (1999) como responsável pela compartimentalização da produção do conhecimento em disciplinas - caminhando, portanto, na contramão da inter/transdisciplinaridade. Esse projeto positivista consolidou um caminho teórico-metodológico de ensino em que se privilegia o conhecimento já produzido, ou seja, as abstrações intelectuais situadas na herança cultural, em detrimento dos acontecimentos concretos da vida humana em sociedade. Em outras palavras, é mais legítimo reproduzir conhecimentos já dados, para apreensão do mundo (movimento de reconhecimento de abstrações gramaticais ou estruturais em textos, por exemplo), do que produzir novos conhecimentos.

Bakhtin (1997), em sua filosofia do ato, já apontava para esse movimento de reprodução de conhecimentos no próprio fazer-científico de seu tempo, na medida em que o compreendia como um "pensamento indiferente" do mundo teórico, ou como "pensamento abstrato", no qual não havia espaço para as ações concretas, reais, singulares, irrepetíveis dos sujeitos, no mundo da vida e da arte: "É impossível qualquer orientação prática de minha vida no mundo teórico, no qual não se pode viver, nem atuar responsavelmente; eu não sou necessário neste mundo, não estou nele por princípio2" (BAKHTIN, 1997, p. 17).

$\mathrm{Na}$ década de 1980, como mostra Soares (2002), com outros contextos sociopolítico e epistemológico (movimentos de redemocratização do país e consolidação da Linguística como componente de formação de professores, cuja entrada nos cursos de Letras se deu na década de 1960, dentre outros), começaram a surgir discursos de mudança em diversos setores da sociedade, inclusive nos da educação. Uma das consequências de tais movimentos é que a disciplina deixou de ser chamada Comunicação e Expressão para voltar a se chamar Lingua Portuguesa. Destaque-se, na área, a publicação em 1984 do livro, hoje clássico, O texto na sala de aula, organizado por João Wanderley Geraldi, que, se não inaugurou, articulou as bases para uma proposta de ensino-aprendizagem de base enunciativo-discursiva, orientada para a formação de leitores e produtores críticos e autônomos. Cabe à escola, por assim dizer, estruturar o fazer-pedagógico de português a partir do trabalho

2 Tradução nossa, a partir da versão espanhola da obra: Hacia una filosofia del acto (BAJTIN, 1997).

BARBOSA, J. P.; SIMÕES, P. H. O. Letramento midiático no ensino de português: 
com as práticas de leitura, produção de textos e análise linguística (GERALDI, 1997a, 1997b), sendo que essa última deve ser orientada para o trabalho com as primeiras, focos centrais da disciplina. De um enfoque funcional e pragmático passa-se para uma abordagem enunciativa e discursiva.

Posteriormente, surgiram no Brasil publicações que acrescentaram à perspectiva enunciativo-discursiva de ensino de português a perspectiva dos letramentos como uma das grandes finalidades de formação na disciplina - com destaque para as obras Os significados do letramento, publicada em 1995 sob organização de Angela Kleiman e Alfabetização e Letramento (1998), organizada por Roxane Rojo.

Ainda durante a década de 1990, sob influência da crescente recepção das obras de Bakhtin no Brasil e dos estudos da Escola de Genebra (DOLZ e SCHNEUWLY, 2004), o conceito de gêneros do discurso veio a ocupar um lugar central na área, tendo sido os gêneros propostos como objetos de ensino pelos Parâmetros Curriculares Nacionais para os anos iniciais e finais do Ensino Fundamental (BRASIL, 1997 e 1998). Assim, conforme os PCN, o ensino de português deve ser orientado pelas práticas de linguagem (leitura, produção de textos e oralidade), o que significa tomar as práticas sociais de uso da linguagem ${ }^{3}$ como referência (e não somente as práticas escolares); deve tomar o texto como unidade de ensino e o gênero como objeto de ensino. Todo esse processo elaborado na articulação da reflexão linguística que parte do uso e desemboca no uso: movimento metodológico uso-reflexão-uso.

Como é possível perceber nos excertos dos $\mathrm{PCN}$ que trazem passagens que fazem referências aso textos jornalísticos (Anexo 1), o trabalho com diferentes gêneros é justificado pela diversidade demandada para atuação em sociedade e, dentro dessa diversidade, sugere-se "aqueles cujo domínio é fundamental à efetiva participação social” e, dentre esses, os da imprensa. A advertência do último parágrafo em relação à especificidade dos gêneros jornalísticos - "senão uma leitura diária, ao menos uma leitura regular dos jornais (...)”, confere um deslocamento,

3 Práticas essas que dizem respeito aos letramentos. Ainda que parte do escopo conceitual esteja presente em algumas passagens dos PCN, optou-se, aqui, pela não inclusão do conceito de letramento em função do seu pouco uso no documento, devido talvez à sua entrada ainda recente na área por ocasião da escrita dos Parâmetros. Essa presença será mais expressiva na $2^{a}$ versão da BNCC, escrita 18 anos depois, comentada adiante. 
Linha D'Água (Online), São Paulo, v. 30, n. 2, p. 71-91, out. 2017

ainda que tímido, do gênero para uma prática letrada de referência - ler jornais regularmente, que frequentemente é ignorada pelas práticas escolares, que estabelecem em seu planejamento gêneros por bimestre/trimestre, por ano, dentre os quais um ou dois jornalísticos e quase nunca abrem espaço para uma leitura de um jornal/site noticioso.

No que tange à esfera jornalística (denominada "imprensa" no documento), os PCN de terceiro e quarto ciclos apontam como gêneros privilegiados nas diferentes práticas: notícia, editorial, artigo, reportagem, carta do leitor, entrevista, charge, tira, comentário radiofônico, debate, depoimento.

A segunda versão preliminar da Base Nacional Comum Curricular (BNCC), grosso modo, preserva a orientação geral de trabalho na área presente nos PCN que destacamos anteriormente. Mas, nesse documento, além de objetivos gerais, há a explicitação detalhada de objetivos específicos - por campo, por prática e por ano - que nem sempre preservam a ênfase nos princípios e pressupostos enunciados ou possibilitam sua concretização. ${ }^{4}$ Nessa versão da BNCC, os gêneros jornalísticos estão situados no Campo Político-Cidadão, assim definido:

[...] campo de atuação que diz respeito à participação em situações de leitura/ escuta, produção oral/sinalizada/escrita, especialmente de textos das esferas jornalística, publicitária, política, jurídica e reivindicatória, contemplando temas que impactam a cidadania e o exercício de direitos. (BRASIL, 2016, p. 92).

São mencionados, a título de exemplo, gêneros que poderão/deverão ser contemplados: noticias ${ }^{5}$, reportagens, cartas do leitor, cartas ao leitor, artigos de opinião,

4 Cabe dizer que as condições de produção da BNCC - fortemente marcadas por interesses mercadológicos (produção de livros e materiais didáticos, cursos de formação de professores etc.) e pela política educacional centrada nas avaliações - obrigou a um nível grande de detalhamento em termos de objetivos de aprendizagem bem como ao estabelecimento de critérios de progressão bastante questionáveis e que tendem a uma excessiva formalização, normatização e/ou artificialidade. Caberia sim a um documento dessa natureza estabelecer objetivos e critérios de progressão, mas não necessariamente com esse grau de detalhamento, que tende a uma padronização excessiva e tecnicista.

5 A designação dos gêneros foi mantida tal e qual aparece no documento. Cabe notar a confusão conceitual entre a designação do gênero e a referência a exemplares de textos. $O$ primeiro deveria sempre vir no singular. O plural deveria ser usado apenas quando da referência

BARBOSA, J. P.; SIMÕES, P. H. O. Letramento midiático no ensino de português: 
Linha D'Água (Online), São Paulo, v. 30, n. 2, p. 71-91, out. 2017

editoriais, charges, propagandas, anúncios, classificados, panfletos, cartazes, fóruns, depoimentos, comentários, podcast, debate. Como se pode perceber no Anexo 2, o recorte dos objetivos relativos a esses gêneros diz respeito, basicamente, à adequação quanto aos elementos e estruturas dos gêneros e a aspectos da textualidade. ${ }^{6}$ Mesmo quando se considera a análise crítica (EF07LP09), a mesma aparece direcionada a um elemento do gênero notícia, o lide: "Analisar criticamente informações que constituem o lide (...)”. Em relação ao restante do texto das notícias isso não se aplicaria? Tal recorte acaba por destacar um dos elementos da estrutura da notícia e não a análise de informação.

No eixo leitura, preponderam as habilidades de revozeamento - reconhecimento e identificação, em detrimento das práticas de apreciação e réplica. No eixo escrita, a grande preocupação parece ser a adequação ao gênero e à situação de comunicação, o que acentua uma perspectiva mais pragmática, funcional e adaptativa de letramento (versão fraca de letramento); e menos crítica, autoral e ativa, na perspectiva de uma versão forte de letramento (cf. SOARES, 1998).

Cabe notar também que, embora haja um intervalo de 18 anos entre os PCN e a BNCC, e que nesse período as tecnologias digitais de informação e comunicação (TDIC) tenham possibilitado/incrementado novas práticas letradas, novos gêneros tenham surgido e outros se transformado e estudos na área de letramento tenham dado destaque para os novos e multiletramentos, os gêneros considerados nos dois documentos são praticamente os mesmos, havendo apenas a inclusão de podcast dentre os gêneros do eixo da oralidade da BNCC, o que corrobora a tendência, já comentada, de estabelecer que a escola deva se voltar somente para o conhecimento já produzido, já sedimentado.

a exemplares de textos e não quando da designação de uma forma de dizer ou de um tipo relativamente estável de enunciado.

- Cabe dizer que o documento traz, além dos objetivos específicos, objetivos gerais da área, da disciplina e do eixo, que consideram aspectos relativos à discursividade e que conferem ao aluno uma atitude mais ativa, como por exemplo "(EFF2LIO7) Formular questionamentos, argumentar e posicionar-se diante de situações que envolvam as dimensões éticas, estéticas e políticas, mobilizando conhecimento das linguagens". Mas o fato disso não aparecer no detaIhamento dos objetivos, quando há uma opção por esse detalhamento, acaba provocando uma inversão de ênfases e dificultando a concretização dos pressupostos enunciados.

BARBOSA, J. P.; SIMÕES, P. H. O. Letramento midiático no ensino de português: 
Para além de outros gêneros a considerar, como álbum noticioso, fotorreportagem, reportagem multimídia, meme, political remix, vlog, dentre outros, outras tantas práticas e ações próprias da esfera jornalística poderiam ser consideradas. Mas, dada a presença marcante dos gêneros nos currículos escolares, antes de discutir que práticas e ações seriam essas, vale refletir sobre o trabalho na escola com gêneros jornalísticos: o trabalho a partir dos gêneros da esfera jornalística pode contribuir com o letramento midiático? Como? Que sujeito leitor e produtor de textos se quer formar quando se fala em formação para o letramento midiático?

\section{Gêneros do discurso e ensino: acontecimento e historicidade em diálogo}

Segundo Bakhtin (2010), as diferentes formas de ação pela linguagem são elaboradas por meio de gêneros do discurso, que, por sua vez, estão situados em diferentes esferas de atividades humanas. Decorreu desse lugar teórico a compreensão dos gêneros do discurso como objetos de ensino da língua portuguesa ${ }^{7}$, primordialmente a partir da publicação dos PCN. Alguns autores (MARTINS, 2008, 2009; GERALDI, 2010: FIORIN, 2006; RODRIGUES, 2014; BARBOSA, 2012) no entanto, têm criticado a forma de abordagem didática dos gêneros, nesses documentos, bem como o próprio processo de didatização de gêneros reveladas em atividades, materiais didáticos e relatos docentes, argumentando que essa didatização, em currículos e práticas, foge à concepção bakhtiniana de gêneros como tipos relativamente estáveis de enunciados. Geraldi (2010) chega a afirmar que o trabalho "visível" com gêneros tem servido de espaço para que o espírito normativo do ensino de língua reencontre seu lugar.

7 É preciso enfatizar que os $\mathrm{PCN}$, embora façam alusão ao pensamento de Bakhtin e do Círculo, foi fortemente influenciado pelo Interacionismo Sócio-Discursivo (DOLZ e SCHNEUWLY, 2004), conferindo ao conceito de "gênero do discurso" uma nova gênese na proposição de sua didatização: "Ao se apropriarem do conceito de gênero de discurso do Círculo de Bakhtin para efeitos de didatização, os PCN realizam, portanto, tanto uma operação de desarticulação do conceito de seu espaço de sentido original, como uma rearticulação do conceito com outros já presentes nesta esfera de comunicação escolar (documentos educacionais oficiais, teorias de didática de língua materna), que dão gênese a um novo conceito e não somente a um novo uso do conceito" (ROJO, 2008, p. 94-95, grifos da autora). 
O autor argumenta que, com base no projeto positivista de ciência, anteriormente mencionado, o mesmo movimento de reprodução de conhecimentos sobre a língua (abstrações gramaticais), para fins de reconhecimento em textos, ocorre no trabalho com gêneros, se entendermos que esse trabalho oferece ao aluno conhecimentos sobre os gêneros para serem, também, reconhecidos. Geraldi (2010), nesse sentido, enfatiza a necessidade de o ensino de português estar orientado para a formulação de perguntas-problema em torno dos acontecimentos de linguagem, possibilitando ao aluno a posição-sujeito de procurar respostas para as hipóteses que formula sobre a língua (e, acrescentamos, outras linguagens) e não a de encontrar nas abstrações das descrições linguísticas, da gramática e/ou da estabilização dos gêneros, as respostas já dadas para perguntas não formuladas.

Seguindo a crítica de Geraldi (2010), mas, também, o pensamento de autores que têm defendido um trabalho, de fato, enunciativo-discursivo com gêneros (ROJO, 2008; RODRIGUES, 2014; ROJO e BARBOSA, 2015), vamos defender, aqui, que, antes de servir de "produto palatável” à tradição (GERALDI, 2010), os gêneros sejam compreendidos como "universais concretos" (ROJO e BARBOSA, 2015), cuja abordagem em sala de aula não se dê pelo viés da estabilização dos usos da linguagem, caracterizada pela atividade objetivante, mas pelo viés da historicidade discursiva enquanto condição para o acontecimento dos enunciados.

Como defende Bakhtin e o Círculo (BAKHTIN, 1997, 2010; BAKHTIN [VOLOSHINOV], 2006), os enunciados concretos, na mesma medida que são singulares, porque produzidos em situações interlocutivas irrepetíveis, por sujeitos únicos (que refratam os discursos a sua maneira, a partir de suas vivências únicas de vida), são, também, sócio-históricos, porque, quando das situações interlocutivas, os sujeitos constroem apreciações valorativas retomando outras vozes, dialogando com discursos que lhes constituíram ao longo das interações de sua vida. Nesse processo de diálogo com discursos outros, os sujeitos retomam, apreciativamente, temas (principal elemento dos enunciados); ou seja, projetos de dizer apreciativos/ volitivos; estilos de dizer e formas composicionais típicas das práticas discursivas instauradas nas esferas. A organização, não dissociada, desses três elementos (tema, estilo e composição) é o que Bakhtin (2010) vai chamar de gêneros do discurso. 
Gêneros, portanto, não são agrupamentos de características já dadas pelo pensamento científico - não são "universais abstratos" (cf. ROJO e BARBOSA, 2015); gêneros são os típicos modos de operar com a linguagem sócio-historicamente elaborados no interior das esferas discursivas; são as estabilizações relativas de uma série de acontecimentos de enunciados concretos, com temas, estilos e composições articulados e situados na esteira do diálogo. $\mathrm{O}$ trabalho com gêneros, em sala de aula, pode se revelar importante se for concebido como trabalho com a bistoricidade de usos da linguagem, responsável pela orientação dos sujeitos quando das escolhas temáticas, estilísticas e composicionais que realizam, de forma responsiva ${ }^{8}$, para elaborar seu projeto de dizer; o acontecimento de seu enunciado; como afirma o próprio Bakhtin (2010, p. 301): "o querer-dizer do locutor se realiza acima de tudo na escolha de um gênero discursivo”.

Assim, no que se refere ao trabalho com gêneros da esfera jornalística, não caberia ofertar aos alunos respostas já prontas para perguntas que eles não formularam (GERALDI, 2010), nem mobilizar as características dos gêneros, dadas pela atividade objetivante, para fins de reconhecimento em textos, em atividades de leitura e de produção textual. Caberia, sim, orientar os alunos a questionarem, de forma crítica, a constitutividade singular (do acontecimento) e a sócio-histórica dos usos da linguagem, estabilizados relativamente em algum gênero e situados em tempos-espaço específicos.

Esse trabalho só fará sentido se a abordagem dos gêneros estiver em sintonia com a problematização das esferas de que fazem parte. Nesse caso, da esfera jornalística ${ }^{9}$. Tomando por base a compreensão de como se estruturou essa esfera,

8 É preciso enfatizar que, ao retomar temas, composições e estilos, os sujeitos não o fazem de forma transparente, reproduzindo-os; mas, sim, de forma responsiva, valorando-os, o que, inclusive, confere à estabilidade de usos da linguagem, ou seja, aos gêneros, sua condição relativa, dinâmica.

9 Pode-se levar os alunos a compreender como a esfera se constituiu ao longo da história (promovendo, inclusive, uma abordagem inter/transdisciplinar com as contribuições de outras áreas do saber sobre a mídia jornalística); quais seus sistemas de atividades (participantes, hierarquias, relações de poder); quais suas práticas discursivas típicas (práticas de noticiabilidade/informatividade; práticas de comentário/opinião). É a partir desse conhecimento que se poderá entender como o universo jornalístico orienta usos da linguagem, produzindo estabilidades relativas de modos de operar com a linguagem.

BARBOSA, J. P.; SIMÕES, P. H. O. Letramento midiático no ensino de português: 
Linha D'Água (Online), São Paulo, v. 30, n. 2, p. 71-91, out. 2017

no Brasil, algo comentado no próximo item, pode-se questionar, em sala de aula, o porquê de determinados usos terem se constituído enquanto regra (no sentido de regularidades de usos) no interior dessa esfera, "confeccionando" estabilidades relativas ou gêneros do discurso. Ou seja, quais interesses, ações apreciativas, ideologias perpassam a elaboração sócio-histórica das regularidades de usos. Por que, por exemplo, adjetivos são pouco usados em notícias? Possibilita à notícia reforçar o ethos jornalístico de neutralidade e transparência? Qual tom volitivo estrutura esse processo, ao longo da história? Não se trata, apenas, de apresentar características do gênero notícia, mas, realizada a leitura de uma notícia e compreendido seu projeto de dizer, trata-se de explorar a compreensão dos valores que perpassam os usos recorrentes, relativamente estáveis, desse gênero.

Tanto em atividades de leitura quanto de produção de textos, sempre atravessadas pela análise linguística, o que se procurará desenvolver é a responsividade, a contrapalavra do aluno, em face das questões éticas, estéticas e políticas que venham a ser problematizadas em sala de aula. Ou seja, a atenção central é sobre o acontecimento das situações interlocutivas, entendendo, é claro, que o acontecimento está, inevitavelmente, forjado no diálogo responsivo com outros dizeres (temas) e formas de dizer (estilos e composições); está sempre elaborado em algum gênero. É nessa perspectiva que se pode dizer que o trabalho com gêneros pode contribuir com o letramento midiático, mas está longe de ser condição suficiente. Como no marco conceitual bakthiniano, o conceito de gênero reclama o de esfera.

\section{Letramento midiático: para além do trabalho com os gêneros jornalísticos}

Como vimos, a entrada do texto jornalístico na aula de português está situada no contexto político da ditadura militar, período em que ocorreu o boom de abertura de empresas de comunicação no Brasil e, com isso, o alargamento da estrutura da esfera jornalística brasileira, através de grandes corporações empresariais que passaram a monopolizar (e ainda monopolizam até hoje) a maior parte dos veículos de comunicação do país (a chamada grande mídia). Esses veículos, "quando privados, são empresas capitalistas de comunicação, que, portanto, objetivam o lucro" (FONSECA, 2004, p. 14), o que faz de seus discursos (informativos e opinativos)

BARBOSA, J. P.; SIMÕES, P. H. O. Letramento midiático no ensino de português: 
Linha D'Água (Online), São Paulo, v. 30, n. 2, p. 71-91, out. 2017

verdadeiras mercadorias. Contraditoriamente, foi em nome da liberdade de expressão, um dos princípios do Estado Democrático de Direito assegurados na Constituição de 1988 no movimento de redemocratização, que não foram regulamentadas formas de "regulação" desse mercado, através de leis e órgãos reguladores ${ }^{10}$, e sua própria democratização, de modo a contribuir com a desconstrução da monopolização midiática brasileira. Esse fato, segundo Fonseca (2004), assegurou

a permissividade dos meios de comunicação, sob pena da legitimação de um efetivo poder sem controle e mesmo de um pensamento único; essa permissividade, em nome da liberdade de expressão, atua como verdadeira máquina de produção do consenso, podendo, no limite, "suprimir" vozes discordantes (FONSECA, 2004, p. 15 , grifos acrescidos).

Destaque-se que essa monopolização foi consagrada no diálogo entre os interesses da ditadura militar, no controle da mídia, e das empresas de comunicação, quanto ao desenvolvimento tecnológico dos meios. Conforme Sodré (1996), esse desenvolvimento empreendido pelo regime resultou em concessões arbitrárias a determinadas corporações empresariais, sobretudo as de radiodifusão, o que gerou a face do monopólio midiático brasileiro de hoje: a detenção de $90 \%$ do que se produz em termos de comunicação por apenas nove clãs familiares. Clãs, esses, de orientações ideológicas comuns ou muito próximas: "o rótulo conservador pode ser atribuído à maior parte das empresas de jornalismo no Brasil que se colocam como porta-vozes e participantes diretas dos interesses e valores secularmente dominantes” (BONINI, 2013, p. 104). Vale dizer que a ação do monopólio não se dá somente por via direta de manipulação de informação ou opinião, mas pela própria manutenção (e destaque) de pautas que passariam, por essa razão, a ser consideradas de maior relevância pela população. ${ }^{11}$

10 Fonseca (2004) faz uma analogia, por exemplo, com os órgãos controladores dos demais produtos de mercado, como "as procuradorias do consumidor (PROCONs), a Secretaria de Direito Econômico (SDE), as agências de regulação setoriais (como a Agência Nacional de Telefonia - ANATEL - e a Agência Nacional de Energia Elétrica - ANEEL), entre outros órgãos, além de entidades privadas sem fins lucrativos, como o Instituto de Defesa do Consumidor (IDEC) - apenas para citar alguns" (FONSECA, 2004, p. 15).

11 Um exemplo recente permite ilustrar essa dinâmica. A reforma do ensino médio proposta

BARBOSA, J. P.; SIMÕES, P. H. O. Letramento midiático no ensino de português: 
$\mathrm{Na}$ contramão da monopolização, começaram a se constituir iniciativas independentes que apresentam alternativas quanto ao modo hegemônico de fazer jornalismo. Segundo Fonseca (2004), é o caso de meios como Carta Capital, Carta Maior, Observatório da Imprensa. Hoje, podemos encontrar novos grupos alternativos que têm surgido, sobretudo, através das redes sociais de internet, como o Mídia Ninja e o Jornalistas Independentes.

No início do milênio, em face do surgimento de novas práticas de letramentos através do meio digital, possibilitadas pela WEB 2.0, a esfera jornalística passa a funcionar a partir de um novo ethos (ROJO e BARBOSA, 2013), ainda que parte do antigo continue convivendo, de forma adaptada, com espaços discursivos que permitem alternativas ao monopólio comunicativo do rádio, da TV e do periódico impresso e que podem conferir um papel mais ativo, reflexivo, colaborativo e participativo para os leitores, que também passam a poder ser produtores. Isso não significa que o monopólio tenha deixado de existir. Existe uma ilusão de que as fontes (primárias) se multiplicam, mas há muito do mesmo da internet (é preciso ser proativo e seletivo para encontrar a diversidade). Além disso, há fontes não confiáveis que disponibilizam notícias falsas e/ou sem critérios/cuidados editorias. Saber avaliar essas fontes, procurar (efetivamente) fontes diversas, para além do monopólio da grande mídia, contrastar informações, enfoques e opiniões, publicar notícias, comentários, textos de opinião, vlogs etc. na rede, levando em conta a dimensão ética e política, passam a ser ações necessárias que deveriam ser da alçada da escola.

Os tempos atuais nos trazem outras formas de impor o consenso ou de rechaçar o dissenso. Os algoritmos das redes sociais produzem o que alguns teóricos da cultura digital têm chamado de efeito bolha - as pessoas interagem cada vez mais com o semelhante e menos com o diferente. Em função da proteção direta da face, não são raras manifestações agressivas e desrespeitosas na rede aos que pensam de outra maneira.

pelo Governo Temer não permaneceu em destaque na mídia durante meses, o que produziu um efeito urgência na matéria e quase que naturalizou a forma antidemocrática com que foi imposta: por uma medida provisória.

BARBOSA, J. P.; SIMÕES, P. H. O. Letramento midiático no ensino de português: 
Linha D'Água (Online), São Paulo, v. 30, n. 2, p. 71-91, out. 2017

Cabe considerar o papel da imprensa na manutenção da democracia. Paul Starr, professor de sociologia de Princeton, afirma o seguinte em debate publicado no jornal Folba de S. Paulo:

A democracia depende da cobertura noticiosa independente de todos os níveis de governo, especialmente os níveis que respondem diretamente aos eleitores. As pesquisas em ciências sociais mostram que, onde a mídia noticiosa é fraca, a corrupção está muito mais presente. Sem uma imprensa independente capaz de cobrar responsabilidade dos governos locais e estaduais, o projeto básico de uma democracia federal fica comprometido.

Não por acaso, o movimento Yo soy 132, ocorrido no México em 2012, reivindicou a democratização dos meios de comunicação e a produção de um terceiro debate televisivo entre os candidatos a presidente. Já não basta somente compreender o que é dito e até mesmo os vários, por vezes conflituosos, sentidos do que é dito. A concretização da democracia exige reflexões sobre o papel da mídia e análise contínua de seu comportamento.

Nesse contexto, é necessário compreender que o letramento midiático vai além de um trabalho com gêneros jornalísticos ou do desenvolvimento de habilidades específicas e imediatas aos atos de leitura e produção de textos (no âmbito do modelo autônomo de letramento), envolvendo práticas de letramentos "indissoluvelmente ligadas às estruturas culturais e de poder da sociedade” (STREET, 1984) e instauradas em contextos diversos (no âmbito do modelo ideológico de letramento).

Assim, para além de formar sujeitos aptos a atenderem às exigências sociais já dadas (versão fraca de letramento), é preciso voltar-se para a formação de sujeitos que venham a desenvolver compreensão crítica e réplica ativa frente aos discursos produzidos e reproduzidos nas práticas de letramentos. Em outras palavras, essa "versão forte" possibilita aos alunos o lugar-sujeito daquele que, com autonomia e maior empoderamento, desvela as apreciações valorativas dos projetos de dizer dos discursos que circulam em sociedade, forjados em relações de poder.

Operar sobre o desenvolvimento dos letramentos midiáticos de nossos alunos, nesse sentido, significa formá-los para a leitura reflexiva, para a elaboração da contrapalavra crítica, da réplica consciente e ativa, de modo que não seja persuadido e 
Linha D'Água (Online), São Paulo, v. 30, n. 2, p. 71-91, out. 2017

manipulado sempre para o consenso, mas que saiba polemizar com os discursos do jornal, comparar pontos de vista, assumir posicionamentos em torno das questões éticas, estéticas e políticas sobre as quais esses discursos tematizam, desmitificando o imaginário alimentado pelo discurso midiático hegemônico de que é possível se fazer jornalismo neutro e transparente.

É importante destacar, por fim, que a formação para esse letramento não deve se dar somente com discursos da grande mídia, mas também com os das mídias alternativas (como as anteriormente citadas e, também, as de culturas locais: rádios e jornais comunitários, jornal da escola etc.), de modo que os alunos desenvolvam, em suas práticas, a orientação para a leitura responsiva dos diferentes modos apreciativos de elaborar, discursivamente, a realidade e para a produção contextualizada de textos jornalísticos.

\section{Considerações finais}

Discursos constroem verdades e realidades sociais; elaboram e reproduzem valores, concepções, formas de ver o mundo e nele agir. A esfera jornalística é uma das instâncias mais atuantes nesse processo, legitimando determinados posicionamentos, veiculando valores e ideologias, na maior parte das vezes com as vestes da falsa neutralidade. Transformar versões em fatos; acusações em sentenças; criminalizar atores e grupos sociais são alguns dos poderes do discurso jornalístico hegemônico, responsável, via de regra, pela produção do consenso, com pouco espaço para o contraditório. Situar, no ensino de português, o letramento midiático no viés crítico é contribuir com a formação de sujeitos autônomos e empoderados na apreciação valorativa crítica dos discursos dessa esfera, desmitificando o ethos de neutralidade e transparência historicamente sustentado por esse "quarto poder" e se constituindo, enquanto sujeito, nas possibilidades de compreender o mundo e de nele agir de forma crítica, consciente, ativa e responsável.

Para isso, é preciso ir além da reprodução das abstrações produzidas pela atividade objetivante de produção do conhecimento (regras gramaticais, conceitos textuais, características dos gêneros); é preciso ir além do desenvolvimento de habilidades e competências imediatas às práticas de leitura e produção de textos. $\mathrm{O}$ 
Linha D'Água (Online), São Paulo, v. 30, n. 2, p. 71-91, out. 2017

movimento é contrário: o que define a formação de "bons" leitores e produtores de textos é o ter o que dizer; é a sua responsividade - em diálogo, sim, com a herança cultural; entendendo habilidades e competências como meio e não a finalidade. Como lembra Zizek (2008), sobre o materialismo dialético, não se deve partir da "reflexão determinada", mas da "determinação reflexiva". Ou seja, o objetivo não é orientar a reflexão, de nossos alunos, para a abstração já dada, mas ter como determinação o desenvolvimento de reflexões.

\section{Referências}

BAKHTIN, M. [VOLOSHINOV]. Marxismo e Filosofia da Linguagem. São Paulo: Hucitec, 2006.

BAKHTIN, M. Os gêneros do discurso. In: BAKHTIN, M. Estética da criação verbal. São Paulo: Martins Fontes, 5 ed., 2010.

Hacia una filosofia del acto etico. Barcelona: Anthropos, 1997.

BARBOSA, J. P. O trabalho com gêneros na escola: refletindo sobre práticas correntes e vislumbrando novos caminhos. In: BARBOSA, J. P.; ROVAI, C. Gêneros do discurso na escola: rediscutindo princípios e práticas. São Paulo: FTD, 2012.

BONINI, A. Análise crítica de gêneros discursivos no contexto das práticas jornalísticas. In: SEIXAS, L; PINHEIRO, N. F. (orgs.). Gêneros: um diálogo entre Comunicação e Linguística. Florianópolis: Insular, 2013.

BRASIL. Base Nacional Curricular Comum. Brasília: MEC, 2016.

Parâmetros curriculares nacionais: terceiro e quarto ciclos do ensino fundamental: língua portuguesa. Brasília: MEC, 1998.

DOLZ, J.; SCHNEUWLY, B. Gêneros e progressão em expressão oral e escrita - elementos para reflexões sobre uma experiência suíça (francófona). In: ROJO, R.; CORDEIRO, G. (Orgs.) Os gêneros orais e escritos na escola. Campinas: Mercado das Letras, 2004.

FIORIN, J. L. Introdução ao pensamento de Baktbin. São Paulo: Ática, 2006.

BARBOSA, J. P.; SIMÕES, P. H. O. Letramento midiático no ensino de português: 
Linha D'Água (Online), São Paulo, v. 30, n. 2, p. 71-91, out. 2017

FOLHA DE S. PAULO. Debate entre Steven Johnson e Paul Starr ocorrido entre 6 e 18 de abril de 2009. Íntegra do texto disponível em http://m.folha.uol.com.br/ilustrada/2009/05/551660-leia -a-integra-do-debate-entre-steven-johnson-e-paul-starr.shtml. Acesso em: 05 de mar. 2017.

FONSECA, F. C. P. Mídia e democracia: falsas confluências. Revista de Sociologia e Política. Curitiba, 22, p. 13-24, jun. 2004.

GERALDI, J. W. Portos de passagem. São Paulo: Martins Fontes, 1997a.

Unidades básicas do ensino de português. In: GERALDI, J. W. (Org.). O texto na sala de aula. São Paulo: Ática, 1997b.

A aula como acontecimento. São Carlos: Pedro e João Editores, 2010.

KLEIMAN, A. Modelos de letramento e práticas de alfabetização na escola. In: KLEIMAN, A. (org.). Os significados do letramento: uma perspectiva sobre a prática social da escrita. Campinas: Mercado das Letras, 1995.

KLEIMAN, A.; MORAES, S. Leitura e interdisciplinaridade. Campinas: Mercado das Letras, 1999.

MARTINS, M. S. C. Avanços e retrocessos nas propostas para o ensino da língua portuguesa: a didatização dos gêneros do discurso. ANAIS V SIGET, agosto de 2009.

Avanços e retrocessos nas propostas de ensino de língua portuguesa: questões de ideologia e de poder. Linguagem em (Dis) curso, v. 8, n. 3, p. 519-539, set./dez. 2008.

RODRIGUES, R. H. Os gêneros do discurso nas aulas de língua portuguesa: (re) discutindo o tema. In: NASCIMENTO, E. L.; ROJO, R. (orgs.) Gêneros de texto/discurso e os desafios da contemporaneidade. Campinas: Pontes, 2014.

ROJO, R. Gêneros de discurso/texto como objeto de ensino de línguas: um retorno ao trivium? In: SIGNORINI, I. (org.). [Re] Discutir texto, gênero e discurso. São Paulo: Parábola, 2008.

Letramento (s): práticas de letramento em diferentes contextos. In: ROJO, R. Letramentos múltiplos, escola e inclusão social. São Paulo: Parábola, 2009.

BARBOSA, J. P.; SIMÕES, P. H. O. Letramento midiático no ensino de português: 
Linha D'Água (Online), São Paulo, v. 30, n. 2, p. 71-91, out. 2017

ROJO, R; BARBOSA, J. P. Gêneros jornalísticos e novos letramentos: novo ethos, curadoria, redistribuição. In: SEIXAS, L; PINHEIRO, N. F. (orgs.). Gêneros: um diálogo entre Comunicação e Linguística. Florianópolis: Insular, 2013.

Hipermodernidade, multiletramentos e gêneros discursivos. São Paulo: Parábola, 2015.

SOARES, M. Língua escrita, sociedade e cultura: relações, dimensões e perspectivas. In:

Alfabetização e letramento. São Paulo: Contexto, 2014.

Português na escola: história de uma disciplina curricular. In: BAGNO, M. (org.) Linguística da norma. São Paulo: Loyola, 2002.

Letramento: como definir, como avaliar, como medir. In: SOARES, M. Letramento: um tema em três gêneros. Belo Horizonte: Autêntica, 1998.

SODRÉ, Muniz. O social irradiado! Violência urbana, neogrotesco e mídia. São Paulo: Cortez, 1996.

STREET, B. Literacy in theory and practice. Cambridge: Cambridge University Press, 1984.

ZIZEK, S. A visão em paralaxe. São Paulo: Boitempo, 2008.

Recebido em 06/03/2017.

Aprovado em 29/09/2017.

BARBOSA, J. P.; SIMÕES, P. H. O. Letramento midiático no ensino de português: 
Linha D'Água (Online), São Paulo, v. 30, n. 2, p. 71-91, out. 2017

\section{ANEXO 1}

\section{EXCERTOS DOS PARÂMETROS CURRICULARES NACIONAIS DE TERCEIRO E QUARTO CICLOS}

Passagens em que o trabalho com o texto jornalístico é mencionado nos PCN dos anos finais do Ensino Fundamental:

A grande diversidade de gêneros, praticamente ilimitada, impede que a escola trate todos eles como objeto de ensino; assim, uma seleção é necessária. Neste documento, foram priorizados aqueles cujo domínio é fundamental à efetiva participação social, encontrando-se agrupados, em função de sua circulação social, em gêneros literários, de imprensa, publicitários, de divulgação científica, comumente presentes no universo escolar (BRASIL, 1998, p. 53).

Assumir a tarefa de formar leitores impõe à escola a responsabilidade de organizar-se em torno de um projeto educativo comprometido com a intermediação da passagem do leitor de textos facilitados (infantis ou infanto-juvenis) para o leitor de textos de complexidade real, tal como circulam socialmente na literatura e nos jornais; do leitor de adaptações ou de fragmentos para o leitor de textos originais e integrais (BRASIL, 1998, p. 70).

Para considerar a diversidade dos gêneros, não ignorando a diversidade de recepção que supõem, as atividades organizadas para a prática de leitura devem se diferenciar, sob pena de trabalharem contra a formação de leitores. Produzir esquemas e resumos pode ajudar a apreensão dos tópicos mais importantes quando se trata de textos de divulgação científica; no entanto, aplicar tal procedimento a um texto literário é desastroso, pois apagaria o essencial - o tratamento estilístico que o tema recebeu do autor. Também não se formará um leitor de textos de imprensa, do qual se espera, senão uma leitura diária, ao menos uma leitura regular dos jornais, lendo-se notícias apenas no primeiro bimestre (BRASIL, 1998, p. 70).

BARBOSA, J. P.; SIMÕES, P. H. O. Letramento midiático no ensino de português: 
Linha D'Água (Online), São Paulo, v. 30, n. 2, p. 71-91, out. 2017

\section{ANEXO 2}

\section{OBJETIVOS DE APRENDIZAGEM RELATIVOS AOTRABALHO COM TEXTOS JORNALÍSTICOS \\ BNCC - 2a VERSÃO}

Os objetivos relativos aos eixos da leitura e da escrita pertinenentes aos textos jornalísticos nos anos finais do Ensino Fundamental apresentam a seguinte progressão (BRASIL, 2016, p. 348-349; 362-363):

\section{Leitura}

\section{0 ano:}

(EF06LP14) Compreender como as notícias se estruturam (título, subtítulo, lide, corpo da notícia).

(EF06LP15) Identificar recursos linguístico-discursivos de títulos e subtítulos e sua eficácia na construção do sentido global do texto.

\section{7o ano:}

(EF07LP09) Analisar criticamente informações que constituem o lide (o quê, quem, onde, quando, como, por quê) em notícias que circulam em diferentes mídias.

(EF07LP10) Identificar, em notícias, recursos linguístico-discursivos responsáveis pela ordenação dos eventos.

$8^{\circ}$ ano: (EF08LP11) Reconhecer argumentos e contra-argumentos em artigo de opinião.

\section{9o ano:}

(EF09LP11) Avaliar, em depoimentos, entrevistas, editoriais, artigos de opinião, posicionamentos que constroem a argumentação.

(EF09LP12) Reconhecer diferentes tipos de argumentos - de autoridade, por comprovação, por exemplificação, de causa e consequência - em gêneros argumentativos diversos.

BARBOSA, J. P.; SIMÕES, P. H. O. Letramento midiático no ensino de português: 
Linha D'Água (Online), São Paulo, v. 30, n. 2, p. 71-91, out. 2017

\section{Escrita}

\section{0 ano:}

(EF06LP34) Produzir textos de diferentes gêneros - charges, tirinhas, que conjuguem linguagem verbal e não verbal sobre fatos e eventos noticiados em diferentes mídias. EF06LP35) Produzir notícias sobre tema relevante utilizando de forma adequada os elementos do gênero (título, subtítulo, lide, corpo da notícia).

\section{7o ano:}

(EF07LP24)Produzir textos com linguagem adequada e estrutura pertinente ao gênero, que apresentem encaminhamentos para resolução de problemas que afetam a vida comum. (EF07LP25) Justificar posicionamentos utilizando vocabulário pertinente e estruturas sintáticas adequadas à situação de comunicação na produção de gêneros reivindicatórios, por exemplo, carta do leitor.

\section{$8^{\circ}$ ano:}

(EF08LP27) Utilizar argumentos e contraargumentos que apontem com clareza a direção argumentativa que se quer defender em artigo de opinião.

(EF08LP28) Empregar elementos de coesão que marquem relações de oposição, contraste, exemplificação, ênfase, coerentes com o posicionamento sobre o tema.

\section{9o ano:}

(EF09LP23) Produzir artigo de opinião utilizando tipos de argumento e conectores adequados à situação de comunicação.

(EF09LP24) Utilizar diferentes tipos de argumentos - de autoridade, por comprovação, por exemplificação, de causa e consequência na construção de gêneros argumentativos.

BARBOSA, J. P.; SIMÕES, P. H. O. Letramento midiático no ensino de português: 